\title{
COVID-19 PANDEMI DÖNEMINDE DiŞ HEKIMLiĞi EĞiTiMINDE YENI NORMALLER
}

\section{NEW NORMALS IN DENTAL EDUCATION DURING COVID-19 PANDEMIC}

\author{
Özen Doğan Onur ${ }^{1}$ (D), Sabire İşler ${ }^{2}$ (D), Gülsüm Ak ${ }^{1}$ (D), Kadriye Peker $^{3}$ (D), Mustafa Mert Açıkgöz ${ }^{1}$ (i)
}

\author{
${ }^{1}$ İstanbul Üniversitesi Diş Hekimliği Fakültesi, Ağız, Diş ve Çene Cerrahisi Anabilim Dalı, İstanbul, Türkiye \\ ${ }^{2}$ İstanbul Üniversitesi Diş Hekimliği Fakültesi, Protetik Diş Tedavisi Anabilim Dalı, İstanbul, Türkiye \\ ${ }^{3}$ Isstanbul Üniversitesi Diş Hekimliği Fakültesi, Temel Tıp Bilimleri Anabilim Dalı, İstanbul, Türkiye
}

ORCID ID: Ö.D.O. 0000-0003-3659-4464; S.I. 0000-0002-1455-2127; G.A. 0000-0002-3339-1568; K.P. 0000-0003-1436-6508; M.M.A. 0000-0002-2346-1622

Atıf/Citation: Onur OD, Isler S, Ak G, Peker K, Acikgoz MM. New normals in dental education during Covid-19 pandemic. Sağlık Bilimlerinde Ileri Araştırmalar Dergisi 2022;5(1):32-40. https://doi.org/10.26650/JARHS2021-945208

Öz

Diş hekimliği eğitimi, preklinik ve klinik dönemleri içeren, teorik ve pratik uygulamaların birlikte yürütüldüğü beş yıllık zorlu bir süreçte gerçekleşir. COVID-19 pandemisinin diş hekimliği eğitimi, hizmet sunumu, bilimsel araştırmalar üzerinde önemli etkileri olmuştur. En çarpıcı değişim, eğitimde modern bilişim teknolojilerinin kullanması, çevrimiçi öğretim ve değerlendirme biçimlerinin uygulanması, toplumun ağız sağlığının korunması ve geliştirilmesinde odaklanma, tele-diş hekimliği uygulamalarının aktif kullanımı olarak özetlenebilmektedir. Ülkemizde Yükseköğretim Kurulu ve Sağlık Bakanlığı önerileri doğrultusunda diş hekimliği fakülteleri, koruyucu önlemler alarak diş hekimliği eğitimlerine devam etmişlerdir. Diş hekimliği eğitimi içerisinde uygulamalı eğitimler önemli yer tutar. Her ne kadar pandemi sürecine uyum sağlanmaya çalışılsa da öğrencilerin motor fonksiyonlarının gelişimini, bağımsız karar verebilme, çalışma yetkinliğini kazandırmayı hedefleyen pratik uygulamalardaki eksikler nedeniyle bazı etik sorunların ortaya çıktığı açıktır. Bu çalışma pandeminin diş hekimliği eğitimi üzerine olumsuz etkilerini derlerken, ortaya çıkan sorunların giderilmesine yönelik pozitif katkı sağlamayı amaçlamaktadır.

Anahtar Kelimeler: COVID-19 pandemisi, diş hekimliği eğitimi, çevrimiçi eğitim, etik

\section{ABSTRACT}

Dental education takes place in a challenging five-year period, which includes preclinical and clinical periods, and where theoretical and practical applications are carried out together. The COVID-19 pandemic has had significant effects on dental education, service delivery, and scientific research. The most striking change can be summarized as the use of modern information technologies in education, the application of online teaching and assessment forms, the focus on protecting and improving the oral health of the society, and the active use of teledentistry practices. In our country, in line with the recommendations of the Council of Higher Education and the Ministry of Health, dental faculties continued their dentistry education by taking preventive measures. Practical training has an important place in dentistry education. Even with the efforts to adapt to the pandemic process, it is clear that some ethical problems have arisen due to the deficiencies in the practical applications aimed at improving the motor functions of the students, making independent decisions, and gaining working competence. This study aims to make a positive contribution to the elimination of emerging problems while compiling the negative effects of the pandemic on dentistry education.

Keywords: COVID-19 Pandemic, Dental Education, Online Education, Ethics

\section{GiRiş}

Diş hekimliği eğitimi, preklinik ve klinik dönemlerden oluşup teorik ve pratik uygulamalar ile beş yıllık zorlu bir süreçte gerçekleşir. Tıp alanındaki tüm eğitimlerden farklı olarak diş hekimliği öğrencileri preklinik dönemde psikomotor fonksiyonlarını geliştirmek amacıyla laboratuvarda fantom ve simüle modellerde, klinik dönemde ise doğrudan hasta üzerinde uygulamalar yaparlar. Preklinik dönemde 'hands-on' uygulama derslerinin yanı sıra öğrencilerimiz ağırlıklı olarak temel bilimler eğitimi alırlar. İnsan vücudunu tanımanın ilk şartı olan bu modülde öğrenciler başta anatomi, fizyoloji, histoloji, embriyoloji, mikrobiyoloji, patoloji, biyokimya, farmakoloji olmak üzere tıp öğrencileri ile benzer dersleri alırlar. Genel sağlık-ağız diş sağlığı ilişkisi kapsamında hastaya 'Primum non nocere=önce zarar verme' ilkesi ile yaklaşılarak sistemik sağlık sorunu olan hastalara güvenli tedavi hizmeti sunulabilmesi amacıyla medikal diş hekimliği modülü

Sorumlu Yazar/Corresponding Author: Mustafa Mert AÇIKGÖZ E-mail: mertacikgoz@istanbul.edu.tr

Başvuru/Submitted: 31.05.2021 • Kabul/Accepted: 17.08.2021 • Online Yayın/Published Online: 20.10.2021 
içerisinde dahiliye, hematoloji, genel cerrahi, dermatoloji, nöroloji, psikiyatri, kulak-burun-boğaz, adli tıp ve diş hekimliği, göz dersleri verilmektedir (1). Ayrıca mesleki dersleri ile diş hekimliğinin her türlü tedavilerini yapabilecek yeterlilik seviyesine kavuşmaktadırlar. Tüm bu dersler, diş hekimlerinin asepsi ve antisepsi kurallarına uygun şartları sağlayarak tedavilerini gerçekleştirmelerinin yanı sıra acil tıbbi müdahale, travma ve enfeksiyon hastalarına doğru yaklaşım ve ilk müdahale konularında alt yapılarını geliştirmektedir.

11 Mart 2020 tarihinde Dünya Sağlık Örgütü (DSÖ), toplum sağlığını tehdit eden COVID-19 salgınının "pandemi" seviyesine yükseldiğini resmen ilan etmiştir $(1,2)$. Tüm dünyada sağlık sistemi bu yükün karşısında ilk günlerde organize olmak yolunda zorlu sınav vermiş, başta kişisel koruyucu ekipmanlar olmak üzere, aşı konusunda hazırlıksız yakalandığını kabul etmiştir. Kaynakların verimli kullanılması ve pandeminin söndürülmesi adına tüm ülkelerin sağlık kuruluşları yol haritaları belirlemiş ve paylaşmıştır.

Son yıllarda yaşanan SARS ve MERS salgınlarının hiçbirinde diş hekimliği eğitimine ara verilmemiştir. İnsan soyunun geleceğinin bu denli büyük bir tehditle karşı karşıya kaldığı COVID-19 pandemi döneminde;

- Diş hekimleri pandemide sağlık hizmetlerine nasıl katkı verebilir?

- Diş hekimliği eğitimi nasıl sürdürülebilir?

- Diş hekimliği eğitiminin yeniden yapılanması nasıl olmalıdır?'

- Diş hekimliği eğitimi sürecinde öğrenciler, eğiticiler, personel ve hastalar çapraz enfeksiyondan nasıl korunabilir? soruları gündeme gelmiştir.

\section{Küresel Perspektifte Pandeminin Diş Hekimliği Eğitimine Et- kileri ve Normalleşme}

COVID-19 pandemisi, diş hekimliği mesleğinde, hizmet sunumunda, eğitim ve bilimsel araşttrmalarda uzun dönem önemli etkiler yaratmıştır. Bu etkiler, eğitimde modern bilişim teknolojilerin kullanması, çevrimiçi öğretim ve değerlendirme biçimlerinin uygulanması, toplumun ağız sağlığının korunması ve geliştirilmesine odaklanma, hastaların eğitimle güçlendirilmesi, tele-diş hekimliği uygulamalarının meslek pratiğinde aktif kullanımı ve diş hekimliği alanında hasta ve toplum odaklı çalışmalar olarak özetlenebilir (3).

Gerek diş hekimliği eğitimi sırasında gerekse diş hekimliği hizmeti uygulamalarında hasta ile yakın mesafeden yüz yüze çaIışılması, uygulanan tedavilerde çalışma alanının ağız boşluğu olması ve yüksek devirli döner aletlerin, hava su spreylerinin kullanılması, etrafa bol miktarda damlacıkların ve aerosollerin yayılmasına, eşyaların ve yüzeylerin bunlarla teması sonucu fomitlerin gelişmesine yol açmaktadır. Ayrıca hastaların öksürme, öğürme, ağızlarını çalkalama, tedavi sırasında korkudan veya acıdan bağırmaları nedeniyle tedavi işlemleri sırasında damlacıkların çevreye yayılması da söz konusudur. Her bir damlacığın en az 1200 aerosol taşıdığı, COVID-19 pozitif bireylerin maske takmadıklarında veya maskeyi doğru kullanmadıklarında etraflarında $5 \mathrm{~m}$ çapında bir alanda bulunan sağlıklı kişileri enfekte edebilecekleri bildirilmiştir (4). Sosyal mesafe kuralının uygulanamayacağı diş hekimliği eğitimi ve tedavi hizmetleri sürecinde çapraz enfeksiyonların önlenmesine yönelik sıkı tedbirlerin alınması gerekmiş ve bilinmezlerin yoğun olduğu pandeminin ilk günlerinde özel/kamu ayrımı yapılmaksızın tüm kurumlarda diş hekimliği çalışmaları aciller haricinde durdurulmuştur (5). Pandemi nedeniyle Kuzey Amerika'da Mart 2020 tarihinden itibaren diş hekimliği fakültelerinin öğrenci klinikleri kapatılmış, öğrenciler uzaktan eğitim için evlerine gönderilmiş, acil kategorisinde olan hastalara tele-diş hekimliği yöntemi ile belirlenip fakültelerin kadrolu ekipleri tarafindan gerekli hizmet verilmiştir (6). Amerikan Diş Hekimleri Birliği pandeminin ilerleyen günlerinde aciller ile sınırlandırılmış diş hekimliği tedavi hizmetlerinde gerekli tedbirler eşliğinde normalleşme dönemine geçilebileceğini bildirmiştir (7).

Öğrenci kliniklerinin kapanması enfeksiyondan korunmaya önemli katkı sunarken klinik yetkinlik şartlarının oluşturulamamasına sebep olmuş, fakültelerin bu kaybı telafi edecek online eğitim destekli müfredat güncellemeleri yapmasını gerektirmiştir (8).

Pandemi süreci her ne kadar bize zor şartlar yaşatsa da bundan sonra yaşanması muhtemel felaket senaryolarına karşı hazırlanılması gerektiğini de vurgulamış ve 'Diş hekimliği eğitiminde geleceğe yönelik gelişim ne olabilir?' sorusunu gündeme taşımıştrr. Kısa sürede üstesinden gelinebileceği düşünülen pandemi sürecinin uzaması ve ilerleyen zamanda hastalığa yönelik tecrübelerin artması ile diş hekimliği eğitiminin devamlılığının sağlanmasına yönelik çalışmalar başlatılmıştır. Eğitimde yaşanan en büyük değişiklik, teorik derslerin online olarak verilmesi olmuştur. Online eğitimlerde Zoom, Skype, GoToMeeting, Google Meet, Hangout, Google Classroom, WebEx, Microsoft Teams gibi yazılımlardan faydalanılmıştır. Sadece lisans eğitimleri değil, mezuniyet sonrası eğitimlerde kongreler, kurslar online hazırlanmış, geniş kitlelere ulaşılabilen webinarlar düzenlenmiş, senkron/asenkron videolar hazırlanıp izlenmesi sağlanmıştır. Uygulamaların kayda alınıp izlenebilmesi, hasta hizmetlerinin zorlaşth̆̆ı pandemi döneminde mesleki gelişime önemli katkılar sunmuştur. Online sisteme günümüz gençliği derhal uyum sağlamış ve derslere kathlım zamanlarını kendilerine göre yorumlamışlar, istedikleri zamanlarda derslerin video kayıtlarını tekrar izlemişlerdir. Bu yöntemlerin kullanılmasına alışık olmayan öğretim üyeleri ilk başlarda eğitimin bu yöntemler desteğinde sürdürülmesine karşı çekincelerini ifade etmişlerdir. Uzayan pandemi dönemi başka çare olmadığını eğitimcilere net şekilde göstermiştir. Bu gerçekten yola çıkarak derslerin dijital teknoloji eşliğinde hazırlanıp sunulmasında eğitimcilere kolay kullanılabilecek sistemleri kurumun hazırlayıp sunması beklenmektedir. Pandemi döneminde konvansiyonel yöntemler eşliğinde diş hekimliği eğitiminin verilmesi mümkün olmamakla birlikte gelecekte benzer sorunlara karşı hazırlıklı olmak gerektiğinden oluşturulacak karma eğitim modellerinde öğrenciler yaşam boyu eğitim felsefesine mutlaka hazırlanmalıdır $(1,6$, 9-13). 
Diş hekimliğinde online eğitim sistemine öğrencilerin ve eğiticilerin uyumunun değerlendirildiği bir anket çalışmasında öğrencilerin sadece $\% 36.8$ 'inin yüz yüze eğitimi tercih ettikleri, öğrencilerin ve eğiticilerin bu eğitim modeline gelecekte devam edilmesine taraf oldukları bildirilmiştir. Aynı çalışmada online eğitimlerin müfredatta yer alma oranı açısından her iki gruptan elde edilen veriler arasında anlamlı fark saptanmıştır. Öğrenciler $\% 53,2$, eğiticiler $\% 38,6$ oranında istek bildirmişlerdir (14).

Online eğitimler gerçek hasta üzerinde yapılan eğitimlerin avantajlarını tam karşılayamadıkları gibi öğrenciler arasında akran eğitimi yönünden de zayıftır. Uluslararası öğrencileri olan kurumlarda saat farkının derslere katılımda getirdiği zorluklar, teknolojik alt yapıların geliştirilmesi, pahalı sistemlere gereksinim olması ve taşınabilirliğin pek mümkün olmaması gibi sorunları içermesine rağmen artık eğitim hayatımızın bir parçası olmuş$\operatorname{tur}(6,15)$.

Man Hung ve arkadaşlarının \%92.4'ünü doktora öncesi diş hekimliği öğrencilerinin oluşturduğu 145 katılımcı ile COVID-19 enfeksiyonunun diş hekimliği eğitimi üzerine etkisi konulu çaIışmalarında öğrencilerin yoğun stres altında oldukları, klinik eğitimlerinin önemli oranda olumsuz etkilendiğine inandıkları, teorik derslerin yeni teknolojiler eşliğinde online verilmesine çabuk uyum sağladıkları bildirilmiştir (7). Aggarwal ve arkadaşları COVID-19 pandemi döneminde tıp eğitimi ile ilgili yayın oranının sadece $\% 0.7$ seviyesinde olduğunu, gelecekte eğitimin intiyaçlar doğrultusunda yeniden yapılanmasında, bu döneme ait çalışmaların önemli rehber görevi göreceğine inandıklarını bildirmişlerdir (16).

Öğrenciler COVID-19 pandemisi döneminde diş hekimliği eğitiminin preklinik döneminin hands-on (pratik uygulama) çalışmalar yapılamadığı için önemli oranda olumsuz etkilendiğini, klinik dönemde gerçek hasta bakılamamasının da kazanılması beklenen yetkinlikler açısından kayba sebep olduğunu, teorik eğitimlerin bu süreçte pek etkilenmediğini, online olgu tartşmalarının gerçek hastanın yerini tutmasa da tanı koyma, tedavi protokolü geliştirmede karar verme açısından faydası olduğu görüşünde olduklarını bildirmişlerdir (17).

Diş hekimliğinin preklinik dönemi, eğitimin kilit taşını oluşturur. Preklinik dönemde yüz yüze laboratuvar ortamında gerçekleştirilen çalışmalar, kapanma döneminde hocaların önceden hazırladıkları videolar aracılığı ile gerçekleştirilmiştir. Bu aşamada simüle hastalardan, sanal gerçeklik modellerinden faydalanılarak öğrencilerin motor gelişimleri, el becerileri, el-göz koordinasyonları desteklenebilir (13). Sanal gerçeklik modellerinde öksürme, öğürtü refleksi, dil ve tükürük mücadelesi simüle edilerek öğrenciler gerçek hastalara daha iyi hazırlanabilir. Simülasyon örneklerinde haptik teknolojilerin kullanılması lokal anestezi uygulamaları, endodontik tedavi, periodontal tedavi, implant uygulamalarında önemli katkı sunar. Sanal gerçeklik modellerinin anatomi derslerinde ve acil tıbbi müdahale eğitimlerinde önemli yeri bulunmaktadır. 17. Yüzyıldan günümüze kadavra üzerinde verilen anatomi eğitiminde pandemi döneminde sosyal mesafenin korunması gereği kadavra üzerinde diseksiyon çalışmaları yapılamamıştır. Iwanaga ve arkadaşlarının COVID-19 pandemi döneminde anatomi derslerinin veriliş yöntemleri üzerine yapmış oldukları çalışmada derslerin güçlendirilmiş gerçeklik, sanal gerçeklik, haptik teknolojiler ile sürdürülmesi incelenmiş, kadavrada öğrencilerin birebir gerçekleştirdikleri diseksiyonlar sayesinde elde ettikleri kazanımları simülasyonların veremediği, karma yöntemler ile derslerin sunulması görüşü paylaşılmıştır $(18,19)$. Hasta hizmetlerinin pandemiye yönelik enfeksiyon kontrolü şartları gereği yavaşladığı günümüzde teknolojinin sunduğu gelişmiş simülasyon modellerinin katkıları sayesinde daha az sayıda hasta bakılarak yine öğrenci eğitiminde beklenen öğrenim hedeflerine ulaşılabilir.

İlk günlerde gerek eğitim kurumu, gerek öğrenciler hasta temasından ve enfekte olmaktan korkmuş ve klinik uygulamalara dâhil olmayı reddetmişlerdir. Uzayan süreçte tecrübelerin de artmasına paralel öğrenciler daha realistik düşünerek tedbirler eşliğinde tedavi hizmetlerinin devam edebildiğini görmüşler, yetkinlik ve yeterliklerinin gelişmesi için klinik uygulama derslerinin önemini kavramışlar, klinikte çalışmak istediklerini kendileri ifade etmişlerdir.

Diş hekimliği eğitimi programında enfeksiyon kontrolü, asepsi/antisepsi kurallarına yer verilmiş olmakla birlikte aerosol ve damlacıklar yolu ile bu denli hızlı yayılan COVID-19 enfeksiyonu, müfredat güncellemesini gündeme getirmiştir. Enfeksiyon kontrolü eğitimleri çalışanların ve hastaların korunmasına yönelik tedbirleri ve çalışma ortamının hazırlanmasına yönelik işlemleri, donanımları, malzemeleri kapsamalıdır. Diş hekimliği ve dental hijyenist öğrencilerinin pandemi dönemi şartlarına adaptasyonları ile ilgili yapılan bir çalışmada, klinik dönem öğrencilerinin enfeksiyon kontrolü ile ilgili derslere preklinik dönem öğrencilerinden daha fazla ilgi gösterdikleri bildirilmiştir (20).

Kurumların enfeksiyon kontrol komitesinin sorumluluğu yükselmiştir. Enfeksiyon kontrol komiteleri sadece eğitim vermekle kalmamalı, sahada şartlara uygun çalışıldığını izlemelidir. SağIık hizmetlerinde kişisel koruyucu ekipmanlara ulaşmak kadar doğru kullanıımasının sağlanması da önemlidir. El hijyeni, doğru sıra ile giyinme, doğru sıra ile ekipmanın çıkarılması mutlaka üzerinde durulması ve kontrol edilmesi gereken aşamalardır.

Diş hekimliği eğitiminde öğrencilerin bilgi, beceri, tutum yönünden geliştirilmesi hedeflenir. Bu kazanımların kontrolü de sınavlar ile mümkündür. Eğitimin içeriğine ve dönemine göre farklı sınav yöntemleri kullanılmıştr. Fakat pandemi döneminde sınav sistemlerinde de uzaktan eğitimde olduğu gibi online sistemler kullanılmıştır. Hiçbir sistemin klinik uygulamaların ve hands-on kursların yerini tutamadığının bilindiği pandemi sürecinde yetkin diş hekimi mezunları verdiğinden emin olma sorumluluğu eğitim kurumunun omuzuna yüklenmiştir. Sınavlarda başarıIı olabilmek için verilen eğitimin katkısının da yüksek olması gerekir. Online eğitimlerde öğrencilerin kendi sorumlulukları paralelinde derslere katılmaları ve motive olmaları gerekmektedir. Uzaktan eğitimlerde sadece hocanın teorik ders verdiği platformlarda öğrenci inaktif kaldığında eğitimin verimi düşmektedir. Diş hekimliği, gelişen teknolojilerden oldukça fazla etkilenen bir disiplin olduğundan, eğitimin amaçlarından biri olan yaşam boyu eğitim yaklaşımı öğrenciye kazandırılmaktadır. Androgojik 
yaklaşımla hazırlanan probleme dayalı eğitim modellemeleri ile öğrencinin öğrenim hedefini kendisinin koyması, motive olması sağlanmalıdır. Bu nedenle probleme dayalı öğrenme kurguları, küçük grup çalışmaları, eğitim videolarına ön test son test sorularının yerleştirilmesi, dersten önce hocaların dijital bir havuzda notlarını kaynakları ile birlikte yüklediği platformlar aracılığı ile öğrencilerin derslere konu hakkında okuyarak gelmesinin sağlanması (Flipped Classroom), videoları izlediklerinin kontrol edilmesi, verimliliği artıracaktır. Amerikan Diş Hekimliği Eğitimi Birliği (ADEA) bu tür videoların hazırlanması özel olarak üzerinde çalışılması gereken ve zaman alan süreçler olduğundan diğer fakülteler ile paylaşılmasını önermektedir. Objektif yapılandırılmış yazılı klinik sınavların hazırlanmasının güvenilir ölçme/ değerlendirme firsatı sunacağı bildirilmektedir (21).

James Donn ve arkadaşları tıp eğitiminde 40 yılı aşkın süredir kullanılmakta olan objektif yapılandırılmış klinik sınavları Glasgow Üniversitesi Diş Hekimliği Fakültesinde sanal ortamda denemişlerdir. Sınav zoom programı kullanılarak gerçekleştirilmiş, sınav öncesi öğrencilere ve eğiticilere sistemin kullanımına yönelik bilgilendirme yapılmıştır. Zoom programının bu sınav yönteminde de verimli kullanılabildiği, sanal sınavlarda sınav sorularının hazırlanmasının güçlüğü haricinde bir zorluk yaşanmadığı bildirilmiştir (22).

Almanya Kuzey Ren Westfalya Sağlık Bakanlığı üniversitelerle birlikte diş hekimliği öğrencilerinin eyalet yetkinlik sınavının sosyal mesafenin korunması ve kapanma şartlarının ihlal edilmemesi amacıyla online yapılması kararını almışlardır. Wicht ve arkadaşları bu yeni sınav yöntemini bir önceki yılın sınav sonuçları ile karşılaştırmışlardır. Öğrencilerden pratik sınavda fantom çeneler üzerinde anterior ve posterior dişlerde restoratif tedavi, endodontik tedavi ve periodontal tedavi gerçekleştirmeleri istenmiştir. Öğrenciler fantom çenelerde daha fazla zorlandıklarını, performanslarını gerçek hastalarda olduğundan daha kötü sergilediklerini ifade etmişlerdir. Çalışmada bu yorumun nedeni olarak fantom çenelerde öğrencilerin yapmış oldukları işi daha detaylı inceleme şansına sahip olmalarının sebep olabileceği düşünülmüştür. Teorik sınav tüm öğrencilere eşit zamanda aynı sorular ile online yapılmış olup her iki yıla ait benzer sonuçlara ulaşıldığı bildirilmiştir. Bu çalışmanın sonucunda ölçme değerlendirmeye etik açıdan yaklaşıldığında, tüm öğrencilerin eşit şartlarda sınava dâhil olmalarının hakkaniyetli olduğu, gelecekte bu yöntemin devamının düşünülebileceği görüşü paylaşılmıştır (23).

Birleşik Arap Emirlikleri'nde yetkinlik sınavında dört günlük süreçte öğrencilere 3 gün çoklu sınav yapılandırması çeşitleri ile teorik, bir gün sözlü sınav yapılmıştır. Sınavlarda kullanılan modeller çoktan seçmeli sorular, nesnel yapılandırılmış klinik sınav (OSCE), modifiye yazılı sınav (Modified Essay QuestionsMEQ) tarzında olmuş, bir gün de sözlü sınav yapılmıştır. Online sınavlarda beş öğrenciye bir teknik eleman verilmiş, öğrenciler kendi cep telefonlarından sisteme bağlanmışlar ve sınav boyunca telefonlarını kullanmamaları teknik personel tarafindan güvence altına alınmıştır. İnternet bağlantısı koptuğunda saat durdurulmuş, bağlant yenilenmiş ve öğrenci kaldığı yerden sı- navına devam etmiştir. Sözlü sınavlar yine online olarak öğrenci ile sınav jürisi arasında gerçekleştirilmiştir. Öğrencilerin sınav sonrası geri bildirimleri, daha fazla zamana ihtiyaçları olduğu yönündedir. Araştırmacılar bu yeni sınav tipinde öğrencilerin ve eğiticilerin konuya henüz alışık olmamalarından kaynaklanan kaygılar yaşadıkları, ilerleyen zamanda verimin yükseleceği görüşünde olduklarını bildirmişlerdir (24).

Bu pandemi, diş hekimliği eğitim programlarına teletıp ve diş hekimliği uygulamalarının da dâhil edilerek öğrencilerin bu konudaki bilgi, pratik uygulama ve yetkinlik düzeylerinin arttrılmasının önemini ortaya koymuştur. Diş hekimliği eğitiminde, diş hekimlerinin doğal afetler ve pandemi dönemlerindeki aktif rolleri dikkate alınarak derslerin öğrenme çıktılarının genişletilmesi gerekmektedir. Diş hekimliği birlikleri ve dernekleri, sürekli eğitim programları ile temel yaşam desteği, flebotomi ve ilaç reçeteleme gibi acil sağlık hizmetleri konusunda kurslar düzenlemelidir $(25,26)$.

\section{Ülkemizde Pandeminin Diş Hekimliği Eğitimi Üzerine Etkileri ve Normalleşme}

Ankara Üniversitesi Diş Hekimliği Fakültesi tarafindan online düzenlenen 1. Uluslararası Diş Hekimliği Eğitimi Kongresinde de gerek yurt içi gerekse yurt dışı katılımcılarla bilgi alışverişi yapılmış, uygulamalar ile ilgili paylaşımlar gerçekleştirilmiş, paneller düzenlenmiştir. Tarih itibarı ile henüz kaç diş hekimliği fakültesinde klinik uygulamaların yapıldığı, eğitim şartları konusunda net veriler yoktur. Yurt içi katılımcıların bazıları fakültelerinde öğrencileri klinik uygulamaya almadıklarını belirtirken, bazı yurt dışı katılımcılar, süreçte uygulama gruplarında öğrenci sayılarının düşürülüp grup sayılarının arttırıldığını, uygulama sayılarının azaltıldığını, bazı fakülteler de hafta sonralarını da eğitime dahil ettikleri bilgilerini aktarmıştır.

Pandemi ile birlikte, birçok eğitim alanında olduğu gibi diş hekimliği eğitimi de ülkemizde uzaktan eğitimle karşı karşıya kalmıştır. Mesleki becerinin özellikle 4 ve 5 . sınıflarda sağlandığı eğitim öğretimin uzaktan sağlanamayacağı açıktır. Öğretim üyeleri ve öğrenciler aşina olmadıkları yeni bir eğitim modeline geçerek, süreç içerisinde planla-uygula-kontrol et- önlem al (PUKÖ) döngüsü ile mevcut şartlarda en efektif eğitimi vermeye çalışmıştır. Konuyla ilgili olarak özellikle Sağlık Bakanlığı ve Yüksek Öğretim Kurumu'nun (YÖK) aldıkları kararlar yön verici olmuştur. Bünyesinde uzaktan eğitim fakültesi içeren üniversiteler ilgili fakültelerin alt yapılarını kullanarak eğitimlerini uzaktan vermeye başlamıştır. İstanbul Üniversitesi'nin Açık ve Uzaktan Eğitim Fakültesi'nin alt yapı ve deneyimlerinin desteği, Bilgi İşlem Birimi'nin senkronizasyonu ile birlikte Diş Hekimliği Fakültesi'nde uzaktan eğitime hızlı bir geçiş yapılmıştır. Senkron, asenkron, yüzyüze ders terminolojisi eğitimde yerini almıştır. Her sınıfa ait erişim alanlarına derslerle ilgili makaleler, kaynaklar, sunumlar yüklenerek eğitim materyalleri zenginleştirilmeye çalışılmıştı. Ancak pratik uygulamaların uzaktan yapılabilmesi, becerinin kazandırılabilmesi söz konusu değildir. Yardımcı uygulamalar olabilmesi için kayıt ve canlı yayın bağlantısı sağlayan gözlükler alınarak, örnek klinik/preklinik uygulamalar kaydedilerek canlı/kayıt öğrencilere iletilmiştir. İstanbul 
Üniversitesi'nde, YÖK'ün 06.03.2020 de aldığı karar ile öğretim üyeleri ve personelin seyahat hareketliliğine sınırlamalar getirilmiştir. Uzaktan eğitim alt yapısı bulunmayan üniversiteler için alt yapısı bulunan üniversiteler ile iş birlikleri sağlanmaya çalışılmıştır.

İstanbul Üniversitesi Diş Hekimliği Fakültesinde klinik uygulamalara öğrencilerin dahil olması için, pratik uygulamalar öncesinde staj gruplarına enfeksiyon kontrolü ile ilgili eğitimler verilmiş, öğrencilere kişisel koruyucu ekipmanların (KKE) giyilmesi ve çıkartılması, atılması, değiştirilmesi sürecinde fiilen destek olunmuştur.

Öncelikle lisans öncesi ve sonrası enfeksiyon kontrolü eğitimlerinin tekrar edilmesi, bilgilerin güncellenmesi tavsiye edilmektedir (25).

YÖK, 13.03.2020 tarihinde ülkemizdeki tüm yüksek öğretim kurumlarında 16.03.2020 tarihinden itibaren eğitime üç hafta süre ile ara verildiğini duyurmuştur. YÖK, 23.03.2020 tarihinde; üniversiteler tarafindan hazırlanan dijital ders içeriklerinin 'YÖK Dersleri Platformu' başlığı ile üniversite öğrencilerinin açık erişimine sunulduğunu duyurmuştur. Hızla gelişen pandemi şartları nedeni ile öğrencilerden başka şehirlerdeki evlerine dönenlerin, eğitimin sadece uzaktan yapılabildiği için erişim sağlayamayan öğrencilerin mevcudiyeti nedeni ile YÖK 01.04.2021 tarihinde aldığı kararla öğrencilere kayıt dondurma ve erteleme hakkı tanımıştır.

Diş hekimliği pratiği, planlama ve uygulama aşamalarında hem materyal hem de kullanılan cihazlar alanında hızla gelişen teknoloji ile iç içedir. Günümüzde bilgisayar destekli uygulamalar ve yazılımlarına uyum sağlamak ve kullanıp, geliştirebilir yetkinlikte olmanın önem kazanması göz ardı edilmemiş ve İstanbul Üniversitesi Diş Hekimliği Fakültesi'nde 2020-2021 yılı eğitim öğretim döneminde, yapay zeka ve makine öğrenmesi müfredata dahil edilmiştir.

YÖK, 11.04.2020 tarihinde aldığı kararda, “....kalan uygulama süresinin az olması dikkate alınarak; Diş Hekimliği ve Eczacılık programlarından mezun aşamasında olan öğrencilerin, 20192020 eğitim ve öğretim yılı bahar dönemiyle sınırlı kalmak kaydıyla, staj/uygulama eğitimlerini; Diş Hekimliği ile Eczacılık programlarında yaz dönemi de dahil uygun zamanda sağlık birimlerinde ve serbest eczanelerde koruyucu önlemler alınarak yapabilecekleri" şeklinde bildirmiştir.

i.Ü. Diş Hekimliği Fakültesi'nde öncelikle klinikler pandemi şartlarına göre yeniden düzenlenerek protokoller oluşturulmuş, öğrencilere bilgilendirme eğitimi verilmiş, tüm koruyucu ekipmanlar fakülte tarafindan temin edilmiş, normal şartlarda öğrencilerin sahip olması gereken el aleti ve araçlar tamamen fakülte tarafindan sağlanmış, bilgilendirme posterleri hazırlanmış, koruyucu ekipmanların giyimi ve davranış eğitimleri verilmiş, onam/bilgilendirme formları oluşturulmuş ve belirlenen minimum sayılarla gruplar oluşturularak son sınıf öğrencileri eğitime alınmıştr. Mezuniyete kalan süreçte dört uygulama grubundan oluşan öğrenciler sadece ilgili tek uygulama grubunu içeren disiplinlerde sınırlı uygulamalar yapabilmiştir. Öğrenciler pandemi ile ilgili eğitimi ayrıca pandemi şartlarında uygulamalı olarak tecrübe etmişlerdir.

27.05.2020 tarihinde YÖK, üniversitelerde dijital ortamda gerçekleştirilebilecek sınavların temel ilkelerini yayınlamıştı. i̇.Ü. Diş Hekimliği Fakültesinde, AUZEF in verdiği eğitim ve teknik alt yapı desteği ile tüm sınavlar klasik, çoktan seçmeli, proje, ödev olarak sorunsuz olarak gerçekleştirilebilmiştir. Sınav süreçlerinde kopya olasılığına karşı bazı fakülteler kamera uygulaması yapmış ancak hızlı gelişen pandemi şartlarına bağlı olarak öğrencilerin farklı eğitim çeşitleri ile karşı karşıya kalması, ağırlıkIı olarak fakülte şartlarından uzak kalmaları, iletişimin sadece elektronik veya mobil telefonlar ile olabilmesi gibi şartların da olumsuz etkisi ile büyük tepki göstermelerine yol açmıştır. Her ne kadar elimizde somut veri bulunmasa da gelişen teknolojik imkanların çevrimiçi sınavlarda kopya çekmeye imkan vermesinin, öğrenciler arasında değerlendirme sürecinin objektif yapılmasına gölge düşüreceği düşünülmektedir. Çalışan ve çalışmayan öğrenci arasındaki ayrımın yapılamamasının bir sonucu olarak eğitim kalitesinin düşebileceği gözardı edilmemelidir.

Pandemi, öğrencilerin mezuniyet törenlerini de olumsuz etkilemiştir. i..ü. Diş Hekimliği Fakültesi'nde ortalama 200 mezun olacak öğrenci için pandemi şartlarına uygun mezuniyet töreni de düzenlenmiştir. Üniversitenin Beyazıt kampüsünde bahçe alanı hem öğrenciler hem de öğretim üyeleri için uygun mesafelerde yerleşim planı ve sunum platformu oluşturulmuş, maalesef çocuklarının mezuniyetlerini görmek isteyen ebeveynlerin alınamadığı ancak bu eksikliğin canlı yayınla giderildiği, diplomaların mezun öğrenciye klasik takdiminin geleneksel olamadığı mesafe ile uzatıldığı, ancak öğrencilerin her şeye rağmen mezuniyet coşkusunu yaşayabildikleri bir mezuniyet töreni gerçekleştirilmiştir.

Pandemi şartları eğitim ve iletişimde hızla dijitalleşmeye yol açmış, yeni teknoloji ve uygulamaları öğrenmeyi gerektirmiştir. Süreç içinde gerek öğrencilerle gerek öğretim üyeleriyle dijital ortamda aktif olarak yapılan toplantılarla iletişim sağlanmıştır. Doğal olarak mesai saatleri dijital ortamda akşam saatlerini de kapsamaya başlamıştır.

YÖK, 30.07.2020 tarihinde; Uzaktan Öğretim Uygulamaları, Uygulamalı Eğitimler, Ölçme ve Değerlendirme Uygulamaları, Yabancı Uyruklu Öğrenciler, Toplantılar, Kongreler ve Değişim Programları başlıkları altında çerçeve kararlar ve önerileri içeren 'Küresel Salgında Yeni Normalleşme Süreci' başlıklı rehberi yayınlamıştır. 13.08.2020 tarihinde ise 2020-2021 Eğitim Öğretim Dönemine Yönelik Açıklamayı duyurmuştur. Salgın sürecinin belirsizliğini koruması nedeni ile tüm dünyada 2020-2021 yılında eğitim öğretime ait kesin açıklamalar yapılamamakta, hibrid, uzaktan eğitim yönünde süresi belli olmayan açıklamalar yapılmıştır. Açıklamada, salgının dinamik bir süreç olmaSı, bölgesel ve yerel seyir farklılıklarının, üniversitelerin farklı imkanlara sahip olmaları gibi nedenlerle üniversitelerin farkIı uygulamalar yapmasına firsat verildiği ifade edilmiştir. Tüm üniversitelerin, eğitim öğretim takvimlerini 1 Ekim 2020 tarihi sonrasında başlayacak şekilde planlamaları istenmiştir. i.ü. Diş 
Hekimliği Fakültesi, bu kapsamda i̇.Ü. Rektörlük ve Senatosunun da onayıyla 4 ve 5. sınıf öğrencilerine klinik uygulama yaptırma kararı almıştır. Mevcut klinik alanı, çalışacak tüm personel dahil olmak üzere minimal sayıda klinik uygulama grupları ve kontrollü protokoller oluşturularak eğitim programlanmış ve uygulamaya sokulmuştur. Pandemi şartları ile birlikte ünit alan standardizasyonları da değişmiş dolayısıyla mevcut alanda kullanılabilir ünit sayısı düşerken, uygulama gruplarında yer alan öğrenci sayısının düşmesi fakat grup sayısının artması nedeni ile sınırlı süreler ortaya çıkmıştır. Tüm dünyada olduğu gibi, normal şartlarda öğrencilere belirlenen uygulama sayıları da düşürülmek zorunda kalınmıştır. Kütüphane dijital arşivi geliştirilerek gerek öğretim üyelerinin gerekse öğrencilerin kaynaklara hızla ulaşımı sağlanmıştır.

Pandeminin bir diğer etkisi ise öğrenci yurtlarına olmuştur. Yurtların sınırlı açık olması veya pandemi riskleri nedeni ile ailesi şehir dışında olup yurtlarda kalan öğrenciler, ortak ev kiralamak gibi çözüm arayışlarına da götürmüştür.

2020-2021 eğitim öğretim döneminde fakültemize yeni gelen öğrencilerin aidiyetini kazanma sevincini kaybetmemeleri, okuyacakları fakülteye entegrasyonlarını sağlayabilmek amacıyla dijital entegrasyon düzenlenmiştir. İdari kadro, anabilim dalları tanıtıldıktan sonra fakültemize gelmelerinden duyduğumuz memnuniyet ifade edilmiş, dereceye girenler tanıtılmış eğitim öğretim yönetmeliği, eğitim öğretim koordinatörlüğü tarafindan anlatılmış, kulüpler tek tek kulüp başkanı öğrenciler tarafindan tanıtıımış/üyelikleri anlatılmış, spor faaliyetleri hakkında bilgi verilmiş, farklı eğitim imkânları ile ilgili bilgiler verilmiştir.

Eğitim öğretim yılının başlaması ile birlikte birinci sınıflar dâhil olmak üzere her sınıfi temsil edecek öğrencilerin seçimi sağlanmıştır. Günümüzdeki yaş grubunun eğilim ve özellikleri de değerlendirilerek en aktif iletişimin sağlanabileceği platformlar belirlenerek iletişim grupları oluşturulmuştur.

i.ü. Diş Hekimliği Fakültesi dijitalleşme ile birlikte süreçte, mezun hekimlere de düzenli olarak Web Tabanlı Sürekli Eğitim Programını başlatmış ve sürdürmektedir. 2020-2021 eğitim öğretim döneminde İstanbul Üniversitesi'nin zoom imkânı sağlaması ile birlikte son sınıf öğrencileri ile müfredat dışı vaka tartışmaları, tüm sınıflara ayrı ayrı yine müfredat dışı mesleki sunumlar, tanıtımlar düzenlenmiştir.

Klinik öncesi uygulamalar, kliniğe hazırlık için temel müfredatı oluşturması nedeni ile ayrı bir öneme sahiptir. Bazı öğrenciler elektrikli motor edinerek evlerinde minik laboratuvarlar oluşturmuşlar, öğretim üyeleri ile birlikte birebir zoom dijital platformu üzerinden aktif olarak çalışmışlardır. Elbette süreç içinde her öğrencinin aynı ortamı sağlayamaması farklı şartlara sebep olmuştur.

Pandemi sürecinde gerçekleştirilmeye çalışılan eğitim öğretim uygulamaları etik sorunları da beraberinde getirmiştir. Öğretim üyelerinin bilimsel kaynaklardan faydalanıp, tecrübe ve emeklerini harcayarak, vakalarını kullanarak hazırladıkları dersler dijital ortamda yayılmış ve telif ile ilgili sorunlar doğmuştur. Kullanı- lan vakaların tümünün internette ulaşılabilir olması başka bir etik sorun yaratmıştır. Vakalarda genellikle hastaların, görüntülerinin eğitimde kullanılmasının onayı alınırken yayın izinleri alınmamaktadır.

Yüz yüze eğitim için büyük özen ve çaba harcanırken öğrenci katılımlarının gittikçe düşmesi, katılan öğrencilerin kameralarını açmayıp ekranda kara kutular olarak yer almaları öğretim üyelerinin de motivasyonunun düşmesine neden olmuştur. Öğrencilerin ders video kayıtlarının istedikleri bir saatte izlemeyi isteme eğilimleri, çarpanlı hızlarda seyretmeleri öğrenmekten çok sınava yönelik ezbere yönlendirmiştir. PUKÖ döngüsünde etkin önlemlerin alınabilmesi ise pandeminin yaratmış olduğu olumsuz psikolojik etkiler nedeni ile zorlaşmaktadır.

Pandemi döneminde dijital teknolojilerin eğitime verdiği desteğin kütüphane ayağı da ihmal edilmemelidir. Öğrencilerin ulaşabileceği sitelerin ve dijital kaynakların artırılması önemlidir. Doğrudan klinikte veya laboratuvar ortamında gerçekleştirilen araştırmalar, kaynakların verimli kullanılması, sosyal mesafenin korunması amacıyla durdurulmalı, online erişimli kaynak bazlı çalışmalara yönlenilmelidir. Mutlaka sahada çalışarak sürdürülecek araştırmalarda enfeksiyon kontrol kurallarına sıkı sıkıya sadık kalınmalıdır.

\section{Pandemi Döneminde Diş Hekimliği Eğitimi ve Etik}

Bugüne kadar toplum ağız diş sağlığı derslerinde hep dişlerin ve ağız sağığının korunması hedeflenmiştir. Diş hekimlerinin olağanüstü hallerde sağlık takımının bir üyesi olabileceği, katkı sunabileceği anlaşılmıştır. Bu gerçek, toplum ağız diş sağlığı dersinin müfredatının, öğrenim hedeflerinin güncellenmesini gerektirmiştir. Halk sağlığı derslerinde öğrencilerin gönüllü çalışmasının ve toplumun farklı gelir seviyesinden, farklı kültürel, geleneksel yapılardan gelen hastalar ile etkili iletişim kurmayı ve kendini, mesleğinin varoluş nedenini anlaması sağlanmalıdır. Pandeminin ilk günlerinde diş hekimliği işlemlerinin durdurulması, hastaların enfekte olmaktan korkması, toplu taşıtlara binmeleri sınırlandırıldığı için tedavi merkezlerine ulaşamamaları gibi nedenlerle hastalar düzenli kontrollerini yaptıramamış ve ağız sağlıkları olumsuz etkilenmiştir. Bu gibi zorlu dönemlerde dijital sağlık hizmetlerinin kullanılmasına ağırlık verilmeli, hastalar telefon üzerinden görüntülü görüşmeler ile yönlendirilmeli, bilgilendirilmelidir. Tüm öğrenciler sadece bu pandemi döneminde değil, ileride karşılaşılacak muhtemel pandemi, doğal afet gibi felaket günlerine hazır olmaları amacıyla orofarengeal, nazofarengeal sürüntü ve tükürük örneklerini yöntemine uygun almayı öğrenmeli, çapraz enfeksiyonların önüne geçilmesine katkı sunabilmelidir. Disiplinler arası ve kurum dışı rotasyonlar kurgulanmalıdır. Tele diş hekimliği dersleri ile hastalarla uzaktan iletişim kurup triaj yapma, meslektaşları ile konsültasyon yapma, tanı koyma, tavsiyelerde bulunma, hastayı takip etme yetkinliği kazandırılmalıdır. Tele diş hekimliği uygulamaları özellikle oral kanserlerin erken tanısında, patoloji çalışmalarında önemli katkı sunmaktadır. Gelişen teknoloji ile tele diş hekimliği üzerinden akıllı telefonlara ilave edilen programlar sayesinde tele-mikroskoplar oluşturulmuş, tele-sitoloji yapılabilir hale gelinmiştir $(6,12,27)$.

Pandemi döneminde, diş hekimliği eğitiminde video konsültasyon kliniklerinin daha fazla kullanımı, klinik simülasyon eğitimi, 
yetkinlik odaklı ve çevrimiçi online eğitim ve öğretim yöntemleri ağırlık kazanmıştır $(28,29)$.

\section{Covid-19 Pandemi Sürecinde Diş Hekimliği Eğitimi ile İlgili Tavsiyeler}

COVID-19 pandemisinin yönetilmesinde, biyomedikal yaklaşım yalnız başına yeterli değildir. Biyopsikososyal yaklaşım çerçevesinde, toplum sağlığına yönelik eylemler planlanırken sektörler arası işbirliği, çalışma esnekliği, kapasitesi, sosyal adalet, eşitlik ve insan hakları dikkate alınmalıdır. Geleceğin halk sağlığı iş gücü olacak hekim adaylarının bu konularda etik bir yaklaşımla bilgi ve kritik becerilere sahip olması gerekmektedir. Eğitimciler ve okul yöneticileri tarafindan halk sağlığı eğitiminin özünü oluşturacak bu konular dikkate alınmalı ve eğitimler ve kurslar vasıtası ile öğrencilerin toplum sağlığına yönelik uygulamalardaki bilgi düzeyi, yetkinlik ve becerileri geliştirilmelidir (30).

Diş hekimliği erişimi sınırlı olduğu pandemi döneminde diş hekimliği öğrencilerinin ağız hijyeninin öğretilmesi, doğru bilgilerin topluma iletilebilmesi ve sağlıklı davranış değişiminin sağlanması için modern iletişim tekniklerini kullanarak mevcut halk sağlığı kampanyalarına katılması ve farklı ortamlarda farklı yaş gruplarına ulaşabilmesi toplumun ağız sağlığı ve genel iyilik halinde fark yaratacaktır (31).

Pandemi döneminde diş hekimliği birlikleri, organizasyonları ve diş hekimliği fakülteleri dijital diş hekimliği uygulamaları ile hastaların ve çocukların ağız sağlığını korumak ve geliştirmek için faaliyetlerde bulunmalıdır (32).

Diş hekimliği fakültelerindeki müfredat, pandemi ve afet yardımı ile ilgili yeterlikleri içerecek şekilde genişletilmelidir. Müfredat belirleyiciler, bunlara ek olarak pandemi koşullarında diş hekimliği uygulamaları konusunda da içeriği zenginleştirmelidirler. Gönüllü tıbbi çalışma ve toplum katılımı programları toplum diş hekimliği müfredatının bir parçası haline getirilerek diş hekimi adaylarının pandemi döneminde toplumun farklı kesimlerini sosyal ve kültürel açıdan tanıması, ihtiyaçlarını tespit etmesi, klinik becerilerini toplum uygulamaları ile birleştirmesi, ekip çalışması, iletişim ve liderlik becerilerini geliştirmesi, diş hekimliği hizmeti ile ilgili sosyal ve etik konuları öğrenmesi için imkân sağlayacaktır (25).

Pandemi döneminde, yaşlılar başta olmak üzere toplumda dezavantajlı gruplara yönelik yürütülecek ağız diş sağ lığını geliştirme programlarında başarı elde edebilmek için öğrencilerin bu grupların ağız sağlığı intiyaçlarını bilmesi; toplumun farklı kesimlerinde davranış değişikliği oluşturarak hastalıktan korunmayı sağlayabilmesi için ise onların iletişim ve multisektörel çalışmalar yapma beceri ve yetkinliklerinin arttrılması gereklidir (33).

COVID-19 salgını, diş hekimleri ve toplum için önemli bir risk oluşturmaktadır. COVID-19 salgınının ekonomik ve psikolojik yönü de salgının bu benzeri görülmemiş ve stresli zamanlarda nüfusun geniş kesimlerinin ruh sağlığına zarar verdiği için özel dikkat gerektirmektedir. COVID-19 salgınının dünya çapında diş hekimliği mesleği üzerinde önemli bir etkisi olmasına rağmen, incelememiz yeni normu benimsemek için birçok muayenehane yönetimi yaklaşımını vurgulamaktadır. Diş hekimlerinin bilgiye dayalı kararlar vermesine ve mesleği hem hasta hem de diş hekimliği profesyonelleri için güvenli hale getirmesine yardımcı olmak için kanıta dayalı güvenlik uygulamalarını ve çok sektörlü iş birliğini vurgulayan daha fazla araştırmaya ihtiyaç vardır (34).

Gerçek yaşam bize artık yeni bir dünyaya kapının açıldığını göstermiştir. Yeni normallere geçilmekle birlikte pandeminin sönmediği bu dönemde artk eskiden sürdürdüğümüz geleneksel diş hekimliği eğitim programı yeterli olmayacak, tek başına dijital teknoloji ihtiyacı karşılayamayacaktır. Karma modeller ve ortaya çıkan, çıkması muhtemel ihtiyaçlara yönelik karma programların geliştirilmesi gerekmektedir.

Eğitim kurumları, topluma, öğrencilerine ve ailelerine karşı söz verdikleri yetkinlikte mezun verme sorumluluğundadırlar. Bu konunun güvencesi hakkaniyetli ölçme değerlendirme yöntemlerinin kullanılmasıdır. Uzaktan eğitimde amacına ulaşan ölçme değerlendirmenin yapılabilmesi için sınav yöntemlerinin çeşitlendirilmesi, teknolojik alt yapının geliştirilmesi, sınavları kurgulayan hocalara ve kullanıcılara eğitimler verilmesi gerekmektedir. Uzaktan eğitimin bir parçası olarak yapılan online sınavların güvenliğinin sağlanması, teknik olanaklarla güvenliği arttırılmış sınav ortamının oluşturulması, ders devamlarının arttırılması, kontrolü ve ekran karartmalarının önlenmesine yönelik düzenlemelere ve çalışmalara ihtiyaç vardır. Pandemide uzaktan eğitimin getirdiği dezavantajların önüne geçmek için bazı ülkelerde uygulanan mezuniyet sonrası yetkinlik sınavı bizim ülkemizde de uygulanabilirliği tartışılmalıdır.

\section{SONUÇ}

Olası salgınlara, doğal afetlere her zaman hazırlıklı olunması amacıyla müfredat güncellenmeli, enfeksiyon kontrolü, toplum ağız diş sağı̆̆ı, tele-diş hekimliği dersleri yeniden kurgulanmalıdır. Öğrencilere interdisipliner çalışma alışkanlığı sağlanması ve toplumu, kendini tanıması amacıyla kurum dışı, interdisipliner stajlar konmalıdır. Dijital teknolojinin eğitime katkısı yadsınamaz bir gerçektir. Fakat yüksek maliyet, taşınamaz altyapı ve internet bağımlılığı, eğiten ve eğitilenlerin kullanıcı eğitimlerine ihtiyaç duyması gibi olumsuzluklarının giderilmesi yönünde çözüm üretilmesi gerekecektir. İlerleyen zamanda pandemi günlerinde verilen eğitime yönelik yapılacak retrospektif analizler yeniden yapılanma sürecinde önemli rehber olacaktır.

\section{Hakem Değerlendirmesi: Dış bağımsız.}

Yazar Katkıları: Çalışma Konsepti/Tasarım: Ö.D.O., S.I.,, G.A.,K.P.,M.M.A.; Veri Toplama- Ö.D.O., S.I., G.A.,K.P.,M.M.A.; Veri Analizi/YorumlamaÖ.D.O., S.I.,, G.A.,K.P.,M.M.A.; Yazı Taslağı- Ö.D.O., S.İ., G.A.,K.P.,M.M.A.; İçeriğin Eleştirel İncelemesi- Ö.D.O., S.İ., G.A.,K.P.,M.M.A.; Son Onay ve Sorumluluk- Ö.D.O., S.I.., G.A.,K.P.,M.M.A.

Çıkar Çatışması: Yazarlar çıkar çatı̧sması beyan etmemişlerdir

Finansal Destek: Yazarlar finansal destek beyan etmemişlerdir.

Peer Review: Externally peer-reviewed.

Author Contributions: Conception/Design of Study- Ö.D.O., S.I.., 
G.A.,K.P.,M.M.A.; Data Acquisition- Ö.D.O., S.I.., G.A.,K.P.,M.M.A.; Data Analysis/Interpretation- Ö.D.O., S.I., G.A.,K.P.,M.M.A.; Drafting Manuscript- Ö.D.O., S.I., G.A.,K.P.,M.M.A.; Critical Revision of Manuscript- Ö.D.O., S.I., G.A.,K.P.,M.M.A.; Final Approval and Accountability- Ö.D.O., S.I., G.A.,K.P.,M.M.A.

Conflict of Interest: Authors declared no conflict of interest.

Financial Disclosure: Authors declared no financial support.

\section{KAYNAKLAR}

1. Quin B, Field J, Gorter R, Akota I, Manzanares MC, Paganelli C et al. COVID-19: The immediate response of european academic dental institutions and future implications for dental education. Eur J Dent Educ 2020;24:811-4.

2. WHO. WHO Director-General's opening remarks at the media briefing on COVID-19-11 March 2020. (Cited 10 May 2021) Available from: URL:-https://www.who.int/directorgeneral/ speeches/detail/who-director-generals-opening-remarks-at-themedia-briefing-oncovid-19---11-march-2020.

3. Barabari P, Moharamzadeh K. Novel Coronavirus (COVID-19) and Dentistry-A Comprehensive Review of Literature. Dent J 2020;8(2):53.

4. Salas J, Zafra M. An analysis of three COVID-19 outbreaks: How they happened and how they can be avoided. 2020. (Cited 5 May 2021) Available from: URL: https://english.elpais.com/spanish_ news/2020-06-17/an-analysis-of-threecovid-19-outbreaks-howthey-happened-and-howthey-can-be-avoided.html.

5. T Liang. Handbook of COVID-19 prevention and treatment. The First Affiliated Hospital, Zhejiang University School of Medicine. 2020. (Cited 1 May 2021) Available from URL: https://covid-19. conacyt.mx/jspui/handle/1000/25.

6. David T Wu, Kevin Y Wu, Thomas T Nguyen, Simon D. Tran. The impact of COVID-19 on dental education in North America-Where do we go next? Eur J Dent Educ 2020;24(4):825-27.

7. Hung $M$, Licari FW, Hon ES, Lauren E, Su S,Birmingham WC et al. In an era of uncertainty:Impact of COVID-19 on dental education. J Dent Educ 2021;85:148-56.

8. Desai BK. Clinical implications of the COVID-19 pandemic on dental education. J Dent Educ 2020;84(5): 512.

9. Deery C. The COVID-19 pandemic: implications for dental education. Evid Based Dent 2020;21(2):46-47.

10. Dedeilia A, Sotiropoulos MG, Hanrahan JG, Janga D, Dedeilias P, Sideris M. Medical and Surgical Education Challenges and Innovations in the COVID-19 Era: A Systematic Review. In Vivo 2020;34(3 Suppl):1603-11.

11. Sukhbir SS, Sahoo NK. Pandemic proofing dental education. Med J Armed Forces India 2020;77(Suppl 1):S31-S36.

12. Machado RA, Bonan PRF, Perez DEC, Martelli H. COVID-19 pandemic and the impact on dental education: discussing current and future perspectives. Braz Oral Res 2020;34:e083.

13. Haroon Z, Azad AA, Sharif M, Aslam A, Arshad K et al. COVID-19 Era: Challenges and solutions in dental education. J Coll Physicians Surg Pak 2020;30(10):129-131.

14. Schlenz MA, Schmidt A, Wöstmann B, Krämer N, Schulz-Weidner $N$. Students' and lecturers' perspective on the implementation of online learning in dental education due to SARS-CoV-2 (COVID-19): a cross-sectional study. BMC Medical Education 2020; 20:354.
15. Nasseripour M, Turner J, Rajadurai S, San Diego J, Quinn B , Bartlett A et al. COVID 19 and dental education: Transitioning from a wellestablished synchronous format and face to face teaching to an asynchronous format of dental clinical teaching and learning. J Med Educ Curric Dev 2021;8:1-3.

16. Aggarwal G, Aggarwal S, Robles J, Depasquale JR, Auseon A. Medical education focus in published articles related to COVID-19. Eur Rev Med Pharmacol Sci 2020; 24(14):7905-07.

17. Van Doren EJ, Lee JE, Breitman LS, Chutinan S, Ohyama H. Students' perceptions on dental education in the wake of the COVID-19 pandemic. J Dent Educ 2020;85(Issue S1):1187-89.

18. Iwanaga J, Loukas M, Dumont AS, Tubbs RS. A review of anatomy education during and after the COVID-19 pandemic: Revisiting traditional and modern methods to achieve future innovation. Clin Anat 2021;34(1):108-14.

19. Chang TY, Hong G, Paganelli C, Phantumvanit P, Chang WJ, Shieh YS et al. Innovation of dental education during COVID-19 pandemic. JDS 2021;16(1):15-20.

20. Akinkugbe AA, Garcia DT, Smith CS, Brickhouse TH, Mosavel M. A descriptive pilot study of the immediate impacts of COVID-19 on dental and dental hygiene students' readiness and wellness. J Dent Educ 2021;85(3):401-10.

21. Iyer P, Aziz K, Ojcius DM. Impact of COVID-19 on dental education in the United States. J Dent Educ 2020;84(6):718-22.

22. Donn J, Scott JA, Binnie V, Bell A. A pilot of a Virtual Objective Structured Clinical Examination in dental education. A response to COVID-19. Eur J Dent Educ 2020;25(3):488-94.

23. Wicht MJ, Höfer K, Derman SHM, Noack MJ, Barbe AG. Retrospective investigation of organization and examination results of the state examination in restorative dentistry, endodontology and periodontology under simulated conditions in times of Covid-19 compared to standard conditions when treating patients. GMS J Med Educ 2020;37(7):Doc87.

24. Khalaf K, El-Kishawi M, Moufti MA, Al Kawas S. Introducing a comprehensive high-stake online exam to final-year dental students during the COVID-19 pandemic and evaluation of its effectiveness. Med Educ Online 2020;25(1):1826861.

25. Seneviratne CJ, Lau MWJ, Goh BT. The Role of Dentists in COVID-19 Is Beyond Dentistry: Voluntary Medical Engagements and Future Preparedness. Front Med (Lausanne) 2020; 7:566.

26. Gurgel BCV, Borges SB, Borges REA, Calderon PDS. COVID-19: Perspectives for the management of dental care and education.J Appl Oral Sci 2020;28:e20200358.

27. Ghai S. Teledentistry during COVID-19 pandemic. Diabetes Metab Syndr 2020;14(4):337-9.

28. Coulthard P, Thomson P, Dave M, Coulthard FP, Seoudi N, Hill M. The COVID-19 pandemic and dentistry: the clinical, legal and economic consequences- part 2: consequences of withholding dental care. $\mathrm{Br}$ Dent J 2020;229(12):801-5.

29. Kramer KJ. The COVID-19 Pandemic and Its Impact on Dentistry. Anesth Prog 2020; 67(2):65-6. 
30. Ghaffar A, Rashid SF, Wanyenze RK, et al. Public health education post-COVID-19: a proposal for critical revisions. BMJ Global Health 2021;6(4):e005669.

31. Liu C, Onudiwe F. The 'new normal' in oral health promotion. $\mathrm{Br}$ Dent J 2020;229(10):641-2.

32. FDI. COVID-19: FDI members distributed PPE for dental teams on World Oral Health Day. (Cited 5 May 2021) Available from: URL: https://www.fdiworlddental.org/covid-19-fdi-membersdistributed-ppe-dental-teams-world-oral-health-day.
33. León S, Giacaman RA. COVID-19 and Inequities in Oral Health Care for Older People: An Opportunity for Emerging Paradigms. JDR Clinical \& Translational Research 2020;5(4):290-2.

34. Mahdi SS, Ahmed Z, Allana R, Peretti A, Amenta F, Nadeem Bijle M, Seow LL, Daood U. Pivoting Dental Practice Management during the COVID-19 Pandemic-A Systematic Review. Medicina (Kaunas) 2020;56(12):644. 